\title{
Synthesis of P4VP-b-PBLG Diblock Copolymers and Their Self-Assembly Behavior
}

\author{
Xinshu Huang, Zhen Liu, Xiaohua He* \\ School of Chemistry and Molecular Engineering, East China Normal University, Shanghai, China \\ Email: *xhhe@chem.ecnu.edu.cn
}

How to cite this paper: Huang, X.S., Liu, Z. and He, X.H. (2019) Synthesis of P4VP-b-PBLG Diblock Copolymers and Their Self-Assembly Behavior. Journal of Materials Science and Chemical Engineering, 7, 56-64.

https://doi.org/10.4236/msce.2019.73005

Received: February 18, 2019

Accepted: March 26, 2019

Published: March 29, 2019

Copyright $\odot 2019$ by author(s) and Scientific Research Publishing Inc. This work is licensed under the Creative Commons Attribution International License (CC BY 4.0).

http://creativecommons.org/licenses/by/4.0/

\begin{abstract}
Well-defined P4VP-b-PBLG diblock polymer composed of poly (4-vinylpyridine) (P4VP) and poly ( $\gamma$-benzyl-L-glutamate) (PBLG) was synthesized by click reaction with alkyne- and azide-functionalized homopolymers. Besides, P4VP blocks were synthesized by copper-mediated atom transfer radical polymerization (ATRP) with a chlorine-containing alkyne bifunctional initiator, and the azido-terminated PBLG homopolymers were synthesized by ring-opening polymerization (ROP) of $\gamma$-benzyl-L-glutamate with an amine-containing azide initiator. In addition, the synthesized P4VP-b-PBLG with different block ratios has been characterized by proton nuclear magnetic resonance $\left({ }^{1} \mathrm{H}\right.$ NMR), Gel permeation chromatograph (GPC) and fourier transform infrated spectroscopy (FT-IR). Then, the self-assembly behaviors of P4VP-b-PBLG have been studied by changing parameters like dripping speed and block ratio. The morphologies of self-assembly of spherical, disk-like and ellipsoid-like shape particles have been observed and analyzed by scanning electron microscopy (SEM). These results have provided guidelines for the design of macromolecular self-assembly.
\end{abstract}

\section{Keywords}

Self-Assembly, Poly (4-Vinylpyridine), Polypeptide, Diblock Copolymer

\section{Introduction}

Polypeptide copolymer was a kind of block copolymers based on polypeptide-hybrid which consist of polypeptide blocks and other polymer blocks [1] [2]. The so called polypeptide with desirable biocompatibility usually owned specific characteristics of polypeptide. The main chain formed by amide bonds has the characteristic of secondary structure similar to proteins [3]. Hence, polypeptide copolymer differed from traditional copolymer due to the unique sec- 
ondary conformations ( $\alpha$-helix, $\beta$-sheet) formed by strong intramolecular hydrogen bonds [4]. Benefiting from these excellent performances, polypeptide copolymer could offer ideal template materials for macromolecular self-assembly [5] [6]. As a kind of typical polyelectrolyte, Poly (4-vinylpyridine) (P4VP) has been widely used in medicine, industry and other fields [7] [8] [9]. As research hotspot, P4VP has been reported the unique application in many applications. Peinemann fabricated an integral asymmetric membrane in a fast and one-step process by combining the self-assembly of an amphiphilic block copolymer (PS-b-P4VP) with nonsolvent-induced phase separation. Recently, Wenming Wan described a simple strategy to successfully expand the morphology library of BCP self-assemblies with clews of tubules via self-assembly of the most common diblock copolymer, P4VP-b-PS, in methanol. Besides, PBLG also attracted the attention of chemists in decades. For example, Jiaping Lin etc. discovered that amphiphilic polypeptide block copolymers and polypeptide homopolymers PBLG-b-PEG/PBLG were able to aggregate together into super-helical structures of rods and rings.

\section{Experimenta}

\subsection{Materials}

Triphosgene (Aldrich, 99\%), 1,1,4,7,7-pentamethyldiethylenetriamine (PMDETA, Aldrich, 99\%), ether absolute (A.R. grade), dichloromethane (A.R. grade), isopropanol (A.R. grade) were all purchased from Meryer Chemical Technology Co., Ltd. N,N-dimethylformamide (DMF, A.R. grade), and the other normal solvents were purchased from Shanghai Chemical Reagent and purified by conventional procedures if needed. There were also some materials prepared and processed in our laboratory. $\mathrm{CuCl}$ (Shanghai Chemical Reagent, A.R. grade) was purified by stirring in glacial acetic acid overnight, filtered, washed with ethanol, and then dried in a vacuum oven at $60 \mathrm{C}$ overnight. $\gamma$-Benzyl-L-glutamate was synthesized from L-glutamic acid (Sinopharm Chemical Reagent Co., Ltd., B.R. grade) and benzyl alcohol (Sinopharm Chemical Reagent Co., Ltd., A.R. grade) according to literatures. Poly ( $\gamma$-benzyl-L-glutamate) was synthesized by ring-opening polymerization (ROP) of $\gamma$-benzyl-L-glutamate $\mathrm{N}$-carboxyanhydride from the monomer of $\gamma$-Benzyl-L-glutamate. P4VP (Poly-4-vinylpyridine) was synthesized from 4-vinylpyridine (Aladdin, 97\%) monomer based on atom transfer radical polymerization (ATRP). P4VP-b-PBLG diblock copolymer was synthesized from Poly-4-vinylpyridine and PBLG through Click Chemistry.

\subsection{Synthesis}

The synthetic route [10] of poly (4-vinylpyridine)-b-poly ( $\gamma$-benzyl-L-glutamate) (P4VP-b-PBLG) was illustrated in Figure 1. The synthesis process as follows:

The $\gamma$-benzyl-L-glutamate was synthesized from L-glutamate. Briefly, L-glutamate $(0.204 \mathrm{~mol}, 30.0 \mathrm{~g})$ and benzyl alcohol $(0.278 \mathrm{~mol}, 30.0 \mathrm{~mL})$ were transferred into a dry pear-shaped bottle, then $20 \mathrm{~mL}$ of sulfuric acid with $60 \%$ concentration 


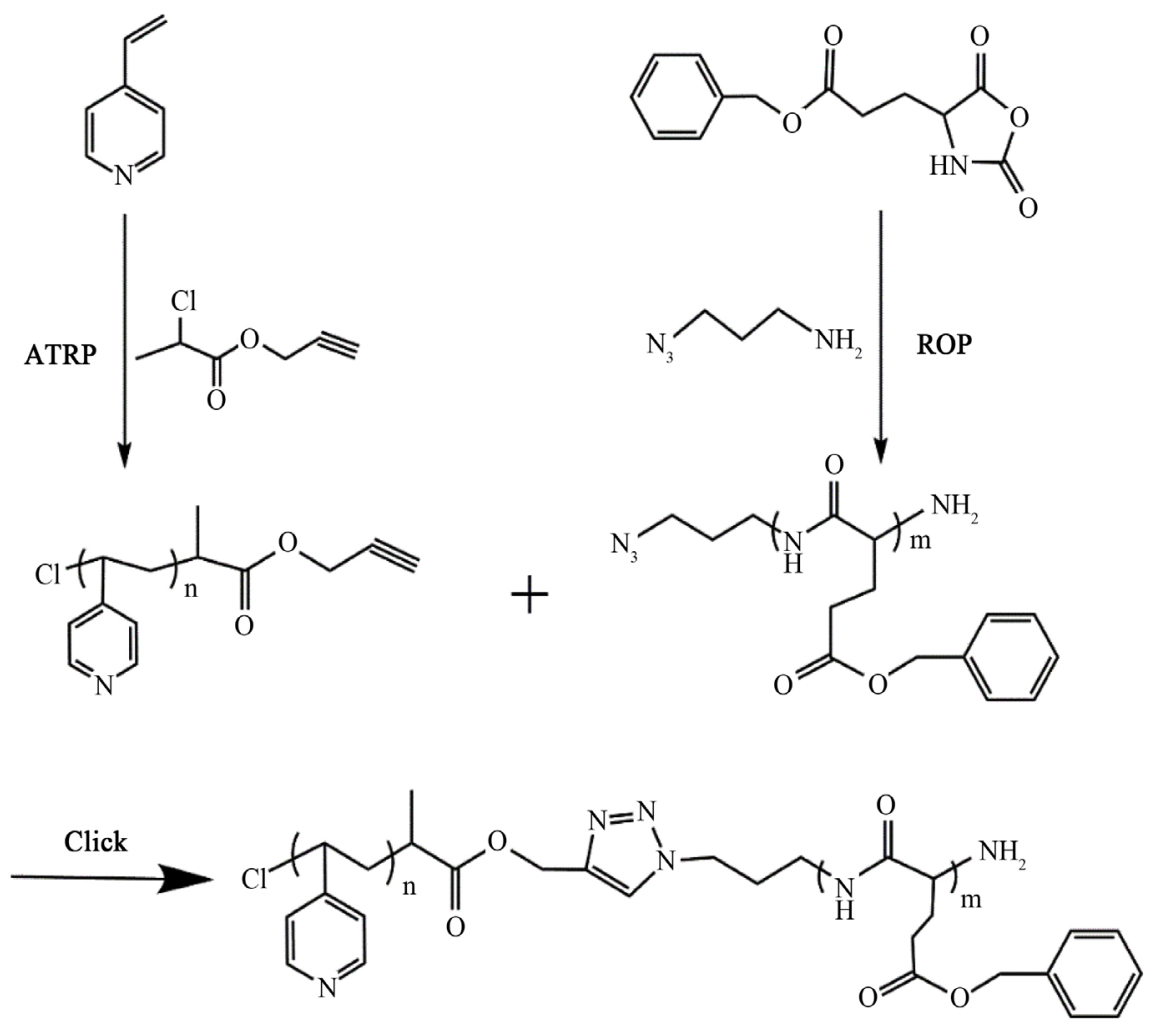

Figure 1. Synthetic route of P4VP-b-PBLG.

was dripped into the bottle under ice water bath. Thereafter, the reaction system was kept under negative pressure for $1.5 \mathrm{~h}$ at $60^{\circ} \mathrm{C}$, followed by adjusting $\mathrm{pH}$ to neutral level. Finally, the resulting product of $\gamma$-benzyl-L-glutamate was purified twice by recrystallization, collected and dried under vacuum.

BLG-NCA was synthesized from $\gamma$-Benzyl-L-glutamate [11]. In detail, $\gamma$ Benzyl-L-glutamate $(34.5 \mathrm{~mol}, 7.67 \mathrm{~g})$, dry-processed ethyl acetate $(200 \mathrm{ml})$ and tri-phosgene ( $14.5 \mathrm{~mol}, 4.30 \mathrm{~g})$ were transferred into a dry schlenk flask in vacuum, followed by reflux reaction for $3 \mathrm{~h}$ under $80^{\circ} \mathrm{C}$ until the system was clear. Then, the mixture was washed twice respectively by $\mathrm{NaHCO}_{3}$ solution (2\%), saturated $\mathrm{NaCl}$ solution and ultrapure water. The organic layer was transferred into a dry conical flask and $\mathrm{MgSO}_{4}$ was added to remove water. Afterwards, the mixture was filtered and poured into a large amount of petroleum ether. The white products were collected by drying precipitation in a vacuum [12] [13] [14].

PBLG-azidehomopolymers were prepared by ring-opening polymerization (ROP) of BLG-NCA. In a round-bottom flask, the dried BLG-NCA (1.09 mol, $0.270 \mathrm{~g})$ and 1-azide 3 -aminopropane $(0.0328 \mathrm{~mol}, 1.21 \mu \mathrm{L})$ were dissolved in anhydrous DMF $(3 \mathrm{~mL})$. The solution was stirred under nitrogen at room temperature in dark for 3 days. Finally, the solution was precipitated into an excess amount of methanol and dried to collect the white products [14].

P4VP-alkyne homopolymers were prepared by atom transfer radical polymerization (ATRP) [15]. Briefly, in an oven-dried Schlenk tube, 4VP monomer (24.0 mmol, $2.52 \mathrm{~g}), \mathrm{CuCl}$ (0.240 mmol, $24.0 \mathrm{mg}$ ), PMDETA (0.240 mmol, 55.2 
$\mathrm{mg})$ and $\alpha$-propyl chloropropionate $(0.240 \mathrm{mmol}, 35.0 \mathrm{mg})$ were dissolved in 2 $\mathrm{ml}$ isopropyl alcohol under nitrogen protection. Then the solution was sealed under vacuum and placed in oil bath for $48 \mathrm{~h}$ at $50^{\circ} \mathrm{C}$. The products were collected by precipitation in anhydrous diethyl ether and purified twice from methanol to diethyl ether. Finally, the products were dissolved in methanol and transferred to dialysis bags for $72 \mathrm{~h}$ to remove copper salts. The brown powder was achieved by drying the dialysate under vacuum overnight.

P4VP-b-PBLG block copolymers were synthesized by click chemistry [16].

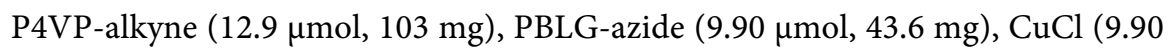
$\mu \mathrm{mol}, 1.00 \mathrm{mg})$ and PMDETA $(9.90 \mu \mathrm{mol}, 2.32 \mathrm{mg})$ were dissolved in $4 \mathrm{ml}$ DMF under nitrogen protection in an oven-dried Schlenk tube. After sealing under vacuum, the solution was stirring for $60 \mathrm{~h}$ at $50^{\circ} \mathrm{C}$ in oil bath. Then the mixture was dropped into diethyl ether for precipitation. After reprecipitating from DMF to diethy ether for three times, the precipitates finally was dissolved in methyl alcohol and transferred to dialysis bags in ultrapure water for $72 \mathrm{~h}$ to remove copper salts. Then the flesh powder was achieved after drying the dialysate under vacuum overnight.

\subsection{Characterization}

The molecular weight and polydispersity of the polymers were recorded on a gel permeation chromatograph (GPC) which equipped with a refractive index detector (Perkin-Elmer Series 200) using DMF $(1 \mathrm{~g} / \mathrm{L} \mathrm{LiBr})$ as the eluent at $45^{\circ} \mathrm{C}$ with a flow rate of $1 \mathrm{~mL} \cdot \mathrm{min}^{-1} .{ }^{1} \mathrm{H}$ NMR spectra were measured by a 500 Bruker NMR instrument and TMS as the reference standard for chemical shifts. Fourier transform infrated spectroscopy (FT-IR) spectra were recorded on Nicolet iS50 and samples mixed with $\mathrm{KBr}$ were pressed into pellets. The elaborate morphologies of self-assembles were obtained from SEM (S-4800, HITACHI) operated at an accelerating voltage of $15.0 \mathrm{kV}$. Before the observation by electron microscope, the samples were coated by a thin layer of sputtered Au on silicon slice.

\section{Results and Discussion}

As shown in Figure 2, the GPC curves of $\mathrm{P}_{4 \mathrm{VP}} \mathrm{P}_{50}-\mathrm{b}-\mathrm{PBLG}_{20}$ and $\mathrm{P} 4 \mathrm{VP} \mathrm{P}_{75}-\mathrm{b}-\mathrm{PBLG}_{20}$ were unimodal and symmetrical, and the elution time were about $18.5 \mathrm{~min}$ and $17.5 \mathrm{~min}$ respectively. These two samples had narrow molecular weight distributions $\left(\mathrm{M}_{\mathrm{n}} / \mathrm{M}_{\mathrm{w}}\right)$, which were 1.21 and 1.28 . When the degree of polymerization increased, the $M_{n}$ also increased from 10,100 to 13,300. It clearly indicated that the higher molecular weight was, the shorter elution time was.

The ${ }^{1} \mathrm{H}$ NMR spectra of P4VP-alkyne was illustrated in Figure 3(A). The chemical shifts of $1 \mathrm{H}$ NMR $\left(500 \mathrm{MHz}, \mathrm{CD}_{3} \mathrm{OD}\right)$ were $8.22\left(\mathrm{a},-\mathrm{CH}-\mathrm{C}_{5} \mathrm{H}_{4} \mathrm{~N}\right), 6.66$ (c, $\left.-\mathrm{CH}-\mathrm{C}_{5} \mathrm{H}_{4} \mathrm{~N}\right), 4.62-4.90\left(\mathrm{~g},-\mathrm{CO}-\mathrm{O}-\mathrm{CH}_{2}-\mathrm{C} \equiv \mathrm{CH},-\mathrm{CCl}-\mathrm{CH}_{2}-\right), 3.18-3.46$ $\left(\mathrm{CD}_{3} \mathrm{OD}\right), 1.32-2.18\left(\mathrm{j},-\mathrm{CHCH}_{3}-\mathrm{CH}_{2}-\mathrm{CHCl}-,-\mathrm{O}-\mathrm{CO}-\mathrm{CHCH}_{3}-\right)$. The resonance signals of protons of pyridine group ( $\mathrm{a}, \mathrm{c}$ ) and $\beta$-methine group (g) appeared. At the same time, each integral ratio of protons was consistent within the error of 


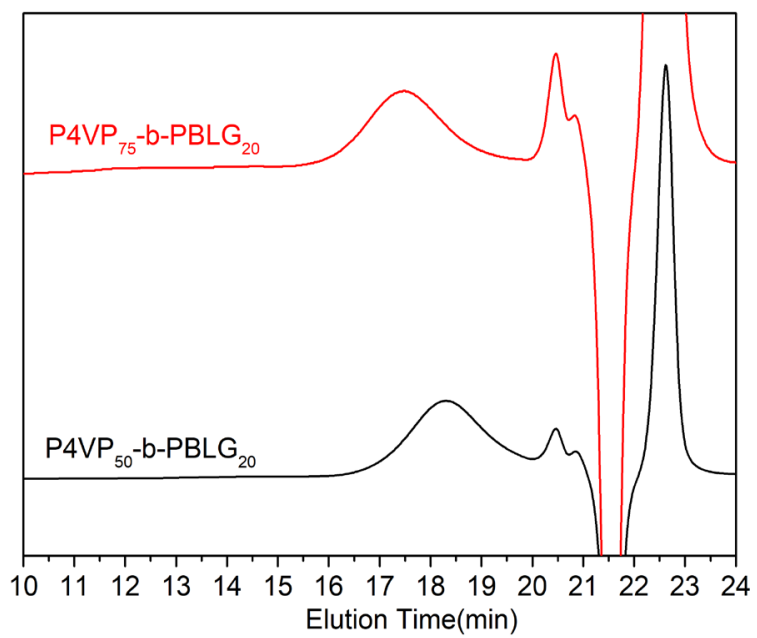

Figure 2. GPC spectra of P4VP-b-PBLG.

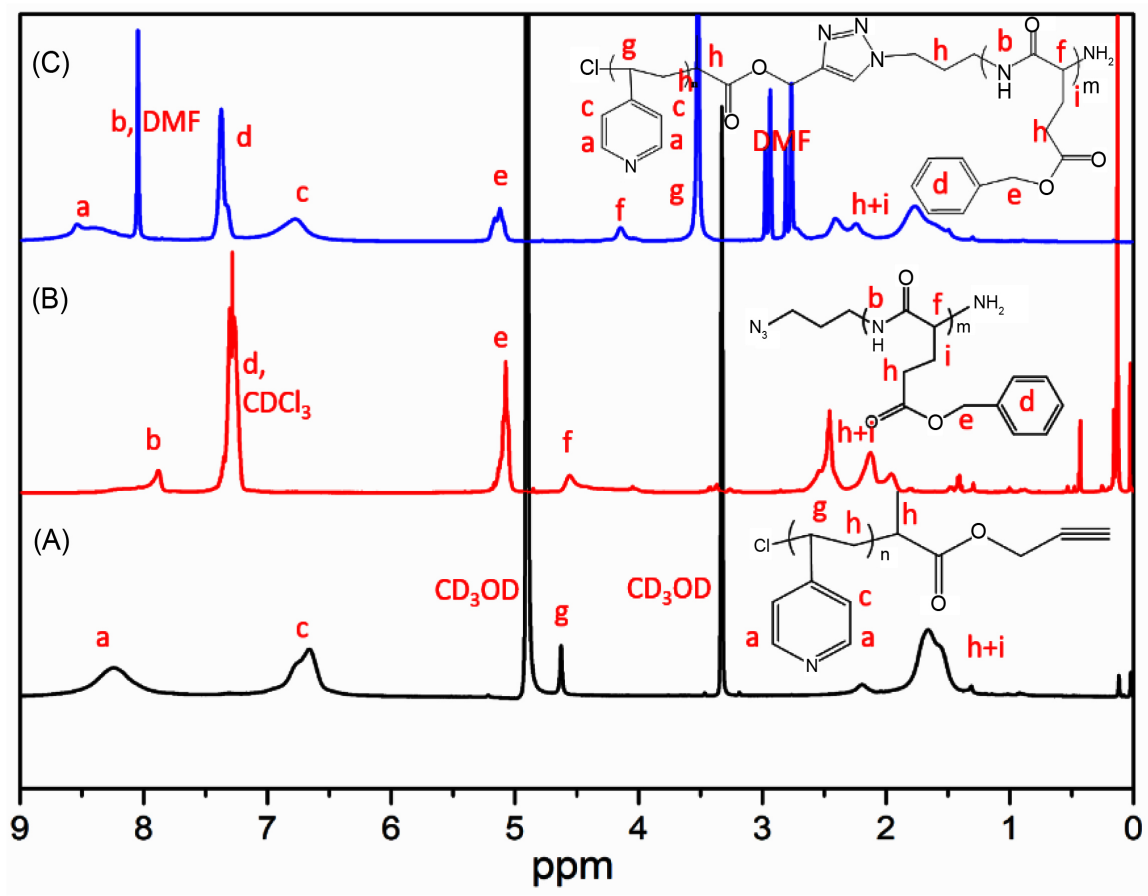

Figure 3. ${ }^{1} \mathrm{H}$ NMR spectra of P4VP-b-PBLG, PBLG-azide and P4VP-alkynyl.

${ }^{1} \mathrm{H}$ NMR measurement.

In addition, the ${ }^{1} \mathrm{H}$ NMR spectra of PBLG-azide was shown in Figure 3(B). The chemical shifts of ${ }^{1} \mathrm{H}$ NMR $\left(500 \mathrm{MHz}, \mathrm{CDCl}_{3}+15 \%\right.$ TFA) were 7.88 (b, -NH-CO-, $-\mathrm{NH}_{2}$ ), 7.28 (d, $-\mathrm{C}_{6} \mathrm{H}_{5}$ ), 5.06 (c, - $\mathrm{O}-\mathrm{CH}_{2}-\mathrm{C}_{6} \mathrm{H}_{5}$ ), 4.56 (f, $\mathrm{N}_{3}-\mathrm{C}_{2} \mathrm{H}_{4}-\mathrm{CH}_{2}-\mathrm{NH}-$ ), 1.27 - 2.48 ( $\mathrm{h}+\mathrm{i}$, -NH-CO-CH- $\mathrm{C}_{2} \mathrm{H}_{4}^{-}, \mathrm{N}_{3}-\mathrm{C}_{2} \mathrm{H}_{4}-\mathrm{CH}_{2}-\mathrm{NH}-$ ). The typical resonance signals of protons of amide group (b), benzyl group(e) and phenyl group (d) were all existent and their integral ratio of protons were consistent within the error of ${ }^{1} \mathrm{H}$ NMR measurement.

${ }^{1}$ HNMR spectra of P4VP-b-PBLG diblock copolymer were also demonstrated in Figure 3(C). The chemical shifts of ${ }^{1} \mathrm{H}$ NMR (500 MHz, DMF) were 8.53 
(a, - $\mathrm{CH}-\mathrm{C}_{5} \mathrm{H}_{4} \mathrm{~N}$ ), 8.05 (b, -NH-CO-CH-,DMF), 7.37 (c, - $\left.\mathrm{CHC}_{5} \mathrm{H}_{4} \mathrm{~N}-\mathrm{CH} 2-\right), 6.77$ (d, - CO-O- $\mathrm{CH}_{2}-\mathrm{C}_{6} \mathrm{H}_{5}$ ), 5.11 (e, - CO-O- $\mathrm{CH}_{2}-\mathrm{C}_{6} \mathrm{H}_{5}$ ), 4.13 (f, - $\mathrm{NH}-\mathrm{CO}-\mathrm{CHCH}_{2}$-), 3.51 (g, $-\mathrm{CHC}_{5} \mathrm{H}_{4} \mathrm{~N}-$ ), $1.77-2.41\left(\mathrm{~h}+\mathrm{i}+\mathrm{j},-\mathrm{NH}-\mathrm{CO}-\mathrm{CH}-\mathrm{C}_{2} \mathrm{H}_{4}^{-}, \mathrm{N}_{3}-\mathrm{C}_{2} \mathrm{H}_{4}-\mathrm{CH}_{2}-\mathrm{NH}-\right.$, -NH-CO-CH- $\left.\mathrm{C}_{2} \mathrm{H}_{4}-, \mathrm{N}_{3}-\mathrm{C}_{2} \mathrm{H}_{4}-\mathrm{CH}_{2}-\mathrm{NH}-\right)$. As shown in Figure 3, both the typical resonance signals of protons of P4VP (8.22 ppm, $6.66 \mathrm{ppm})$ and PBLG (7.28 ppm, $5.06 \mathrm{ppm}, 1.95-2.48 \mathrm{ppm}$ ) could be found in 1H NMR spectra of P2VP-bPBLG block copolymer.

On the other hand, FT-IR spectra of P4VP-alkyne (Figure 4(C)), PBLG-azide (Figure 4(B)) and P4VP-b-PBLG (Figure 4(A)) still proved the successful synthesis of diblock copolymers. The characteristic absorption peaks of the amide bonds and pyridine bonds, which originated from PBLG chain and P4VP chain respectively, could be clearly observed at $1731 \mathrm{~cm}^{-1}, 1655 \mathrm{~cm}^{-1}$ and $1599 \mathrm{~cm}^{-1}$ in the FT-IR spectra of P4VP-b-PBLG. What's more, the terminal azido group of PBLG-azide at $2189 \mathrm{~cm}^{-1}$ disappeared.

Therefore, the characterization results of GPC, ${ }^{1} \mathrm{H}$ NMR and FT-IR proved that P4VP-b-PBLG diblock copolymers had been synthesized successfully.

\section{Self-Assembly Behavior Research}

The main operations of self-assembly were divided into following steps. The morphologies were self-assembled by dripping selective solvent into mother solvent at a certain speed. Herein, the mother solvent was prepared by dissolving P4VP-b-PBLG diblock copolymer in DMF solvent with a certain concentration, and the selection solvent was consisted of ultrapure water. As we all known, DMF and water have different volatilize speeds. In order to prevent the morphology changes caused by different solvent volatilizing rates in drying process, the self-assembly aggregates were transferred into dialysis bags with a certain

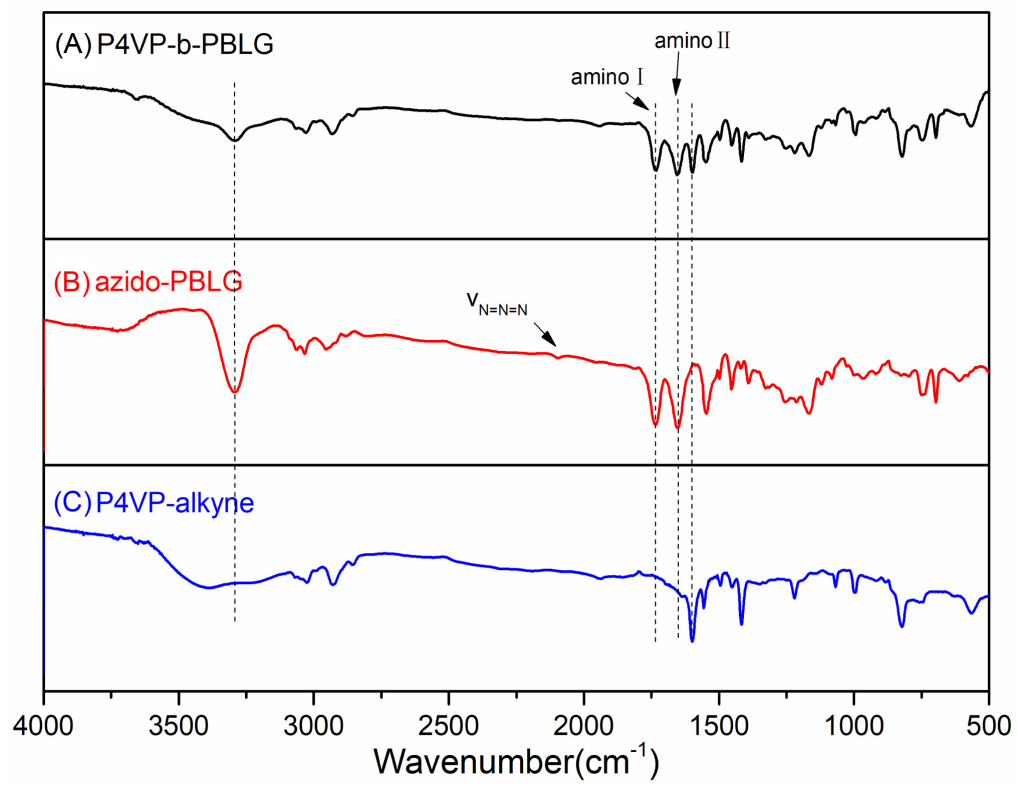

Figure 4. FT-IR spectra of P4VP-b-PBLG, PBLG-azide and P4VP-alkyne. 
trapped molecular weight in ultrapure water for $72 \mathrm{~h}$ to remove the DMF and fix morphology. And then, the self-assembly aggregates after dialysis were dripped on silicon then the self-assembly morphologies can be observed by scanning electron microscope.

After many single factor changing tests, we found that stable self-assembly morphologies can only be prepared when the volume ratio of mother solvent and selective solvent was of 1:1. Besides, concentration of mother solvent, dialysis time and storage time have little influences on morphology changing. However, the morphologies were affected largely by the parameters of polymerization degree and dropping speed.

The dropping speed has a significant influence on morphology of $\mathrm{P}_{4} \mathrm{VP}_{50}$-b$\mathrm{PBLG}_{20}$. The different morphologies resulted from different dripping speeds were illustrated in Figure 5. It was very obvious that the morphologies prefer to be ellipsoid particles at $0.75 \mathrm{ul} / \mathrm{s}$ (Figure 5(A)) and be a disk-like shape at 0.5 $\mathrm{ul} / \mathrm{s}$ (Figure 5(B)), and the dimension of disk-like aggregates was larger than ellipsoid shape particles. It means that the packing method of self-assembly can be affected sensitively by dynamic factors [12].

We have also replaced $\mathrm{P}_{4} \mathrm{VP}_{50}-\mathrm{b}-\mathrm{PBLG}_{20}$ with $\mathrm{P}_{4} \mathrm{VP}_{75}-\mathrm{b}-\mathrm{PBLG}_{20}$ and studied the morphology changing result from dripping speed with different polymerization degree. As shown in Figure 6, the particles were disk-like at $0.75 \mathrm{ul} / \mathrm{s}$ (Figure 6(A)) and spherical at $0.5 \mathrm{ul} / \mathrm{s}$ (Figure 6(B)), however, the dilemmas were closed to each other. The self-assembly would like to be isotropic when the diffusion rate slower than the assembly rate and be anisotropic once the diffusion
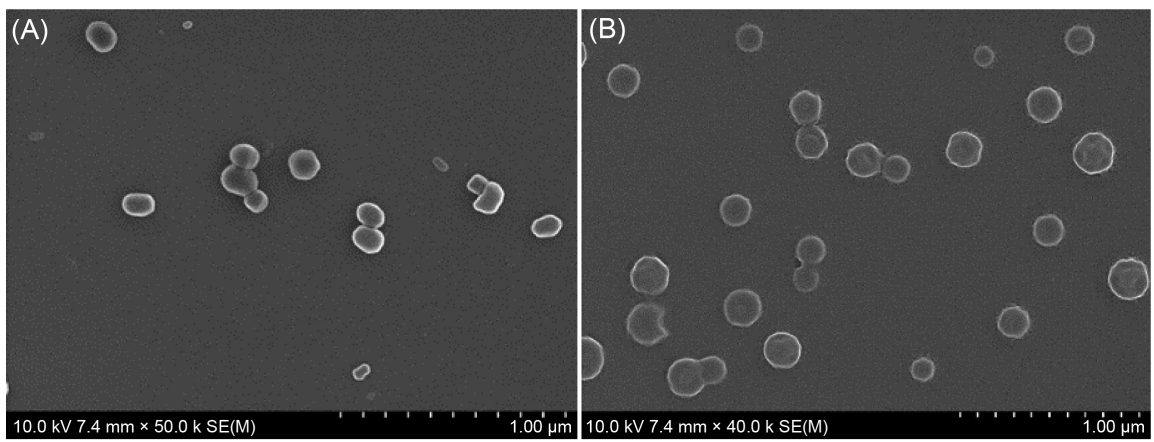

Figure 5. SEM of $\mathrm{P} \mathrm{VP}_{50}-\mathrm{b}-\mathrm{PBLG}_{20}$, (a) $0.75 \mathrm{ul} / \mathrm{s}$ (b) $0.5 \mathrm{ul} / \mathrm{s}$.
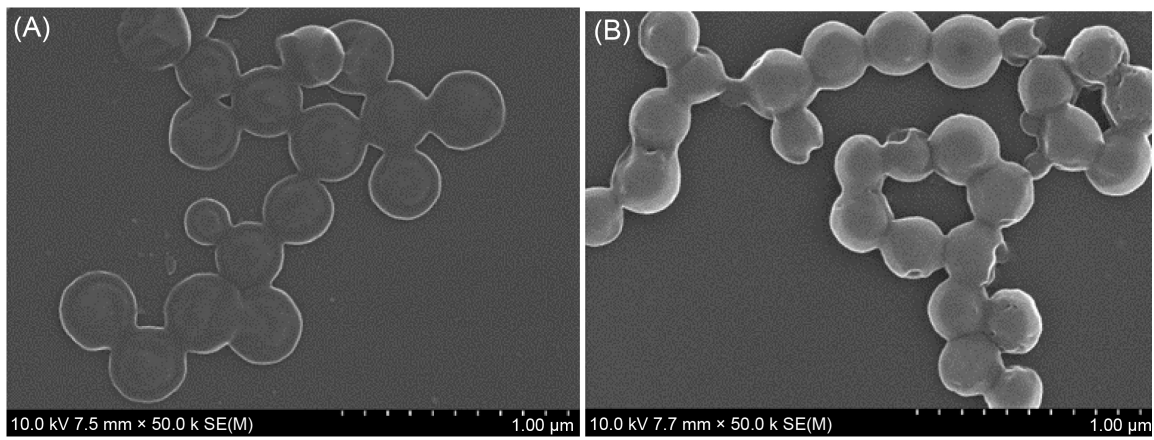

Figure 6. SEM of $\mathrm{P} \mathrm{VP}_{75}-\mathrm{b}-\mathrm{PBLG}_{20}$, (a) $0.75 \mathrm{ul} / \mathrm{s}$ (b) $0.5 \mathrm{ul} / \mathrm{s}$. 
rate faster than assembly rate.

Besides, comparing the differences of morphologies with different polymerization degrees under the same self-assembly parameters, we found that the chain length has a certain contribution to the sizes of self-assemblies although they owned the same hydrophobic PBLG chains. It also means that the PBLG segment acted as the role of core and P4VP as the shell of self-assembles in molecular packing [13].

\section{Conclusion}

In this article, ring-opening polymerization of N-carboxyanhydride (NCA-ROP), copper-mediated atom transfer radical polymerization (ATRP) and click reaction were used to synthesize diblock copolymers P4VP-b-PBLG, which were the first examples of diblock copolymers poly (4-vinylpyridine)-b-polypeptide combining $\mathrm{pH}$-stimulating $\mathrm{P} 4 \mathrm{VP}$ with biocompatible and biodegradable PBLG. Gel permeation chromatograph (GPC), proton nuclear magnetic resonance $\left({ }^{1} \mathrm{HNMR}\right)$ and fourier transform infrared spectroscopy (FT-IR) were used to characterize the structures. Then, self-assembly behaviors of PBLG-b-P4VP were studied by using scanning electron microscope (SEM). Some self-assembly aggregates were obtained from P4VP-b-PBLG, such as disk and sphere etc. We found that the dripping speed affected the morphologies sensitively which means that dynamic factor played a very important role in self-assembly of P4VP-b-PBLG. Because the dripping rate was the most direct parameter to change dynamic factors in self-assembly, which affected the speeds of stretching and curling of hydrophilic and hydrophobic segments. Besides, P4VP were not easy to form strong hydrogen bonds with water molecular which resulted in that the self-assembly process of P4VP-b-PBLG was "slower". On the other hand, the morphologies self-assembled by P4VP-b-PBLG with different hydrophilic polymerization degrees have obvious difference because P4VP segment wrapped outside the aggregates.

\section{Conflicts of Interest}

The authors declare no conflicts of interest regarding the publication of this paper.

\section{Acknowledgements}

This work was financially supported by the National Natural Science Foundation of China (51773063).

\section{References}

[1] Rhodes, A.J. and Deming, T.J. (2013) Soluble, Clickable Polypeptides from AzideContaining N-Carboxyanhydride Monomers. ACS Macro Letters, 2, 351-354. https://doi.org/10.1021/mz4001089

[2] Tang, H.Y. and Zhang, D.H. (2011) Multi-Functionalization of Helical Block Copoly( $\alpha$-Peptide)s by Orthogonal Chemistry. Polymer Chemistry, 2, 1542-1551. https://doi.org/10.1039/c1py00015b 
[3] Rapoport, N. (2007) Physical Stimuli-Responsive Polymeric Micelles for Anti-Cancer Drug Delivery. Progress in Polymer Science, 32, 962-990. https://doi.org/10.1016/j.progpolymsci.2007.05.009

[4] Knoop, R.J.I., de Geus, M., Habraken, G.J.M., Koning, C.E., Menzel, H. and Heise, A. (2010) Stimuli Responsive Peptide Conjugated Polymer Nanoparticles. Macromolecules, 43, 4126-4132. https://doi.org/10.1021/ma100327p

[5] Shim, M.S. and Kwon, Y.J. (2010) Acid-Transforming Polypeptide Micelles for Targeted Nonviral Gene Delivery. Biomaterials, 31, 3404-3413. https://doi.org/10.1016/j.biomaterials.2010.01.019

[6] Zhang, A., Li, J.G., Wang, T., Wu, D.L., Zhang, X.Q., Yan, J.T., Du, S., Guo, Y.F. and Wang, J.T. (2008) Stimuli-Responsive Zwitterionic Block Copolypeptides: Poly(N-Isopropylacrylamide)-Block-Poly(Lysine-Co-Glutamic Acid). Biomacromolecules, 9, 2670-2676. https://doi.org/10.1021/bm800394p

[7] Israelachvili, J.N. (2011) Intermolecular and Surface Forces. Soft Matter, 7, 4122-4138.

[8] Checot, F., Rodriguez-Hernandez, J., Gnanou, Y. and Lecommandoux, S. (2006) Responsive Micelles and Vesicles Based on Polypeptide Diblock Copolymers. Polymers for Advanced Technologies, 17, 782-785. https://doi.org/10.1002/pat.821

[9] Chécot, F., Brûlet, A., Oberdisse, J., Gnanou, Y.O., Mondain-Monval, S. and Lecommandoux, S. (2005) Structure of Polypeptide-Based Diblock Copolymers in Solution: Stimuli-Responsive Vesicles and Micelles. Langmuir, 21, 4308-4315. https://doi.org/10.1021/la0468500

[10] Lee, M., Cho, B.-K. and Zin, W.-C. (2001) Supramolecular Structures from Rod-Coil Block Copolymers. Chemical Reviews, 101, 3869-3892. https://doi.org/10.1021/cr0001131

[11] Kim, K.T., Park, C., Vandermeulen, G.W.M., Rider, D.A., Kim, C., Winnik, M.A. and Manners, I. (2005) Gelation of Helical Polypeptide-Random Coil Diblock Copolymers by a Nanoribbon Mechanism. Angewandte Chemie International Edition, 44, 7964-7968. https://doi.org/10.1002/anie.200502809

[12] Klok, H.A. and Lecommandoux, S. (2006) Solid-State Structure, Organizationand Properties of Peptide-Synthetic Hybrid Block Copolymers. Advances in Polymer Science, 202, 75-111. https://doi.org/10.1007/12_083

[13] Schlaad, H. (2006) Solution Properties of Polypeptide-Based Copolymers. Advances in Polymer Science, 202, 53-73. https://doi.org/10.1007/12_082

[14] Forster, S. and Antonietti, M. (1998) Amphiphilic Block Copolymers in Structure-Controlled Nanomaterial Hybrids. Advanced Materials, 10, 195-217. https://doi.org/10.1002/(SICI)1521-4095(199802)10:3<195::AID-ADMA195>3.0.C $\mathrm{O} ; 2-\mathrm{V}$

[15] Luijten, J., Vorenkamp, E.J. and Schouten, A.J. (2007) Reversible Helix Sense Inversion in Surface-Grafted $\operatorname{Poly}(\beta$-Phenethyl-L-Aspartate) Films. Langmuir, 23, 10772-10778. https://doi.org/10.1021/la7011217

[16] Schlaad, H. and Antonietti, M. (2003) Block Copolymers with Amino Acid Sequences: Molecular Chimeras of Polypeptides and Synthetic Polymers. The European Physical Journal E, 10, 17-23. https://doi.org/10.1140/epje/e2003-00004-3 